TÀI LIÊU THAM KHẢO

1. Kanzaki J, Tos M, Sanna M. Acoustic Neuroma: Consensus on Systems for Reporting Results. Tokyo: Springer; 2003.

2. Mccaslin Electronystagmography/Videonystagmography. San Diego: Plural Publishing; 2013:147-174.

3. Tringali $S$, Charpiot $A$, Ould $M$, al. e. Characteristics of 629 vestibular schwannomas according to preoperative caloric responses. Otology \& Neurotology. 2010;31:467-472.

4. Yingling $C D$, Gardi JN. Intraoperative monitoring of facial and cochlear nerves during acoustic neuroma surgery. 1992. Neurosurg Clin N Am. Apr 2008;19(2):289-315, vii.

5. Gerganov $V$, Nouri $M$, Stieglitz $L$, al. e. Radiological factors related to pre-operative hearing levels in patients with vestibular schwannomas. Journal of Clinical Neuroscience. 2009; 16:1009-1012.

6. Tos M, Thomsen J, Harmsen A. Results of translabyrinthine removal of 300 acoustic neuromas related to tumour size. Acta otolaryngologica. 1988;105(sup452):38-51.

7. Berrettini S, Ravecca F, Sellari-Franceschini S, al e. Acoustic neuroma: correlations between morphology and otoneurological manifestations. Journal of the Neurological Sciences 1996;144:24-33.

8. Kentala E, Pyykko I. Clinical picture of vestibular schwannoma. Auris Nasus Larynx,. 2001;28:15-22.

9. Wang AY, Wang JT, Dexter $M$, al. e. The vestibular schwannoma surgery learning curve mapped by the cumulative summation test for learning curve. Otol Neurotol. 2013;34(8):1469-1475.

\title{
ĐĂC ĐIỂM LÂM SÀNG BÊ̂NH VIÊM LỢI TRÊN PHỤ NỮ CÓ THAI TẠI KHOA SẢN BỆNH VIÊ̂N BẠCH MAI, NĂM 2019-2020
}

\author{
Phan Huy Hoàng ${ }^{1}$, Hoàng Bảo Duy ${ }^{1}$, \\ Hà Ngọc Chiều ${ }^{1}$, Trịnh Thị Thái Hà ${ }^{1}$, Lê Hưng ${ }^{2}$
}

\section{TÓM TẮT}

Mục tiêu: Nhân xét đặc điểm lâm sàng bênh viêm Iợi trên phu nữ có thai tại khoa sản bênh viện Bach Mai - Hà Nồi năm 2019-2020. Phương pháp nghiên cứu: mô tả cắt ngang. Kết quả: phu nữ mang thai chủ yếu mắc viêm lợi mức độ $2(93,6 \%)$. Mức độ viêm lợi với chỉ số GI và mức độ mảng bám với chỉ số PI tăng dần theo tuổi thai. Mức độ viêm lợi cũng tăng theo tuổi phu nữ mang thai. Mức đô viêm lợi ở nhóm răng phía trước (chỉ số $\mathrm{GI}=1,52$ ) nặng hớn so với nhóm răng phía sau (chỉ số GI $=1,25$ ). Kết luân: Hầu hết phụ nữ mang thai bị viêm lợi. Cần tẳng cường, lồng ghép kiến thức chăm sóc sức khoẻ răng miệng vào chương trình chăm sóc sức khỏe sinh sản và cần có những nghiên cứu sâu hơn, rộng hơn về bệnh lý viêm lợi, viêm nha chu trên phụ nữ mang thai để khẳng định và đưa ra các biên pháp dự phòng.

Tư khoá: Viêm lợi, phụ nữ có thai.

\section{SUMMARY}

\section{CLINICAL CHARACTERISTICS OF GINGIVITIS IN PREGNANT WOMEN AT THE OBSTETRICS OF BACH MAI HOSPITAL, 2019-2020}

Objective: To comment on the clinical characteristics of gingivitis in pregnant women at the obstetric department of Bach Mai hospital - Hanoi in 2019-2020. Research method: cross-sectional

${ }^{1}$ Viện Đào tạo Răng Hàm Mặt,Trường Đại học Y Hà Nội ${ }^{2}$ Bệnh viện Đa khoa Đống Đa

Chiu trách nhiệm chính: Phan Huy Hoàng

Email: Nhasixman@gmail.com

Ngày nhận bài: 6.01.2021

Ngày phản biện khoa học: 4.3.2021

Ngày duyệt bài: 15.3.2021 description. Results: Mainly, pregnant women had degree 2 gingivitis (93.6\%). The level of gingivitis with GI and plaque levels with PI increases gradually with gestational age. The level of gingivitis also increases by the age of the pregnant woman. The level of gingivitis in the anterior teeth (GI index $=1.52$ ) was found heavier than that of the posterior ones (GI index $=1.25)$. Conclusion: Most pregnant women suffer gingivitis. It is necessary to strengthen and integrate knowledge of oral health care into the reproductive health care program and conduct deeper and broader studies on gingivitis and periodontitis in pregnant women to confirm and propose preventive measures.

Keywords: Gingivitis, pregnant women.

\section{I. ĐắT VẤN ĐỀ}

Bê̂nh vùng quanh răng là một trong những bệnh phổ biến trong các bệnh răng miệng. Bệnh gặp ở mọi lứa tuổi, mọi quốc gia trên thế giới, chiếm tỷ lê cao trong cộng đồng và mang tính chất xã hôi. Bênh không chỉ gây tổn thương tai chố mà còn ảnh hưởng đến sức khỏe toàn thân và thẩm mỹ của người bệnh. Năm 1986, WHO xếp bệnh quanh răng là hiểm hoa thứ 3 của loài người sau các bênh ung thư, tim mạch. Bênh cũng đã được nhiều tác giải nghiên cứu và chứng minh có mối liên quan với tình trạng sinh non, nhẹ cân thiếu tháng ở phụ nữ mang thai [1],[2].

Viêm lợi là một bệnh lý phổ biến trong nhóm bệnh quanh răng, đây là tổn thương ở giai đoạn khởi đâu và khu trú ở lợi mà chưa thâm nhập vào tổ chức khác của vùng quanh răng. Ở nước ta, theo kết quả điêuu tra sức khỏe răng miệng 
toàn quốc lần thứ 2 năm 2001, tỷ lệ viêm lợi trên cả nước ở độ tuổi 15 là 95,6\%, ơ độ tuổi 35 - 44 là 99,26\%[3]. Viêm lợi ở phụ nữ có thai do nguyên nhân mảng bám răng và các hoóc môn steroid nôii sinh đã làm tăng nặng thêm tình trạng bệnh. Vì vậy, viêm lợi trên phụ nữ có thai có nhiều khác biệt với các viêm lợi thông thường. Tuy nhiên, hiện nay ở nước ta chưa có nhiều nghiên cứu về đề tài này. Vì vậy nghiên cứu được tiến hành nhằm mục tiêu: "Nhận xét đặc điểm lâm sàng bệnh viêm lợi trên phụ nữ có thai tại khoa sản bệnh viện Bạch Mai - Hà Nội năm 2019-2020".

\section{II. ĐỐI TƯợNG VÀ PHƯƠNG PHÁP NGHIÊN CỨU}

\section{1. Đối tượng nghiên cứu}

2.1.1.Tiêu chuẩn lựa chọn

- Phụ nữ mang thai có sức khỏe bình thường

- Tự nguyện và đồng ý tham gia nghiên cứu.

\subsubsection{Tiêu chuẩn loại trừ}

- Đối tượng có nguy cở thai kỳ cao: bệnh tiểu đường, cao huyết áp thai kỳ, tiền sử sảy thai nhiều lần, có bệnh toàn thân khác đi kèm, đang sử dụng kháng sinh, đa thai.

- Không đồng ý tham gia nghiên cứu.

\subsection{Phương pháp nghiên cứu}

- Thiết kế nghiên cứu: nghiên cứu mô tả cắt ngang

- Cõ mẫu:

Áp dụng công thức: $n=Z_{1-\alpha / 2}^{2} \frac{p(1-p)}{d^{2}}$

Trong đó: n: Cỡ mẫu nghiên cứu cân có

p: Tỷ lệ viêm lợi ở phụ nữ mang thai tại Brazil $(p=0,844)[4]$

d: Độ chính xác tuyệt đối (chọn $\mathrm{d}=0,7$ )

$Z^{2}(1-a / 2)$ : hệ số tin cậy, với mức ý nghĩa thống kê $\alpha=0,05$, tương ứng với độ tin cậy là $95 \%$ thì $\mathrm{Z}_{(1-\mathrm{a} / 2)}=1,96$

Dựa vào công thức trên chúng tôi tính được $n=103$, thực tế chúng tôi đã khám và tư vấn cho 110 phụ nữ mang thai.

\subsection{Các bước tiến hành nghiên cứu}

2.3.1. Dụng cụ thu thập số liệu

- Bộ khay khám nha khoa thông thường gồm gương, gắp, thám châm

- Sonde nha chu WHO

- Phiếu khám

- Các dụng cụ sát trùng: bông, côn, găng tay.

2.3.2. Phương pháp thu thập số liệu
- Liên hệ với ban lãnh đạo khoa Sản và phòng Kế hoạch tổng hợp bệnh viện Bạch Mai.

- Các bênhi nhân đến khám tai khoa Sản bênh viện Bach Mai được khám và tư vấn về tình trạng nha chu theo mẫu.

- Cách khám:

+ Phỏng vấn bệnh nhân để thu thập các thông tin về đặc trưng cá nhân và các triệu chứng cơ năng.

+ Đối tượng được khám đánh giá và ghi nhận các thông tin về lâm sàng mô lợi, chỉ số lợi Gi (Gingival Index) và chỉ số mảng bám PI (Plaque Index).

+ Đối tượng được tư vấn và hướng dẫn chăm sóc răng miệng.

2.4. Xử lý số liệu. Nhập dữ liệu bằng phần mềm Epi-data. Xử lý, phẩn tích số liệu bằng phần mềm SPSS 20.0 và một số thuật toán thống kê y học khác.

\subsection{Biện pháp hạn chế sai số}

- Đối tượng nghiên cứu được chọn theo đúng tiêu chuẩn và chỉ tiến hành khi đối tượng hợp tác tốt.

- Phiếu khám được xây dựng theo mục tiêu, dễ thu thập thông tin.

- Nhập số liệu và xử lý số liệu được tiến hành hai lần để đối chiếu kết quả.

2.6. Đạo đức trong nghiên cứu. Nghiên cứu chỉ tiển hành khi được sự đồng ý của Ban Iãnh đạo khoa Sản và Bệnh viện Bạch Mai. Mọi thông tin liên quan đến đối tượng nghiên cứu được giữ bí mật, các số liệu thu thập được chỉ sử dụng vào mục đích nghiên cứu. Đối tượng tham gia nghiên cứu hoàn toàn tự nguyện sau khi được thông báo về mục đích của nghiển cứu, đối tượng có quyền không tiếp tục tham gia nghiên cứu bất kỳ lúc nào nếu muốn. Quá trình khám đảm bảo vô khuẩn, phòng chống lây nhiễm chéo. Tất cả các đối tượng tham gia nghiên cứu đều được tư vấn vệ sinh răng miệng.

\section{KẾT QUẢ NGHIÊN CỨU}

Trong nghiên cứu này, phụ nữ mang thai ở độ tuổi 20-29 chiếm tỷ lệ $51,8 \%$, từ $30-39$ chiếm $36,3 \%$ và từ 40 tuổi trở lên chiếm $11,8 \%$. Phụ nữ trẻ nhất mang thai là 21 tuổi và phụ nữ lớn tuổi nhất mang thai là 45 tuổi. Có $18,2 \%$ phụ nữ mang thai trong 3 tháng đầu, $43,6 \%$ trong 36 tháng và $38,2 \%$ trên 6 tháng. $100 \%$ phụ nữ mang thai bị viêm lợi.

Bảng 3.1. Phân bố mức độ viêm lợi theo tuổi của phụ nữ mang thai

\begin{tabular}{|c|c|c|c|c|c|c|}
\hline \multirow{2}{*}{ Tuổi Mức độ } & \multicolumn{2}{|c|}{ Viêm lợi độ 1 } & \multicolumn{2}{c|}{ Viêm lợi độ 2 } & \multicolumn{2}{c|}{ Viêm lợi độ 3 } \\
\cline { 2 - 7 } & Số lượng & Ty̆ lệ & Số lượng & Tỵ lệy & Số lượng & Tỷ lệ \\
\hline $20-29$ tuối & 4 & 3,6 & 54 & 49,1 & 0 & 0 \\
\hline $30-39$ tuối & 0 & 0 & 33 & 30 & 3 & 2,7 \\
\hline
\end{tabular}




\begin{tabular}{|c|c|c|c|c|c|c|}
\hline$>40$ tuối & 0 & 0 & 16 & 14,6 & 0 & 0 \\
\hline Tống & $\mathbf{4}$ & $\mathbf{3 , 6}$ & $\mathbf{1 0 3}$ & $\mathbf{9 3 , 6}$ & $\mathbf{3}$ & $\mathbf{2 , 7}$ \\
\hline
\end{tabular}

Nhận xét: Viêm lợi mức độ 2 chiếm tỷ lệ cao nhất (93,6\%), trong đó chiếm tỷ lệ cao nhất là phụ nữ mang thai ở độ tuổi 20-29 (49,1\%), tiếp theo là nhóm 30-39 (30,0\%) và nhóm >40 tuổi $(14,6 \%)$. Viêm lợi mức độ 1 và 3 chiếm tỷ lệ thấp và tương đương nhau (3,6\% và 2,7\%). Sự khác biệt không có ý nghĩa thống kê với $\mathrm{p}=0,0629>0,05$.

\section{Bảng 3.2. Phân bố mức đồ viêm lơi theo tuổi thai}

\begin{tabular}{|c|c|c|c|c|c|c|}
\hline \multirow{2}{*}{ Tuổi thaíc độ } & \multicolumn{2}{c|}{ Viêm Iợi độ 1 } & \multicolumn{2}{c|}{ Viêm Iợi độ 2 } & \multicolumn{2}{c|}{ Viêm Iợi độ 3 } \\
\cline { 2 - 7 } & SL & $\mathbf{\%}$ & SL & $\mathbf{\%}$ & SL & \% \\
\hline$<3$ tháng & 4 & 3,6 & 16 & 14,5 & 0 & 0 \\
\hline 3-6 tháng & 0 & 0 & 48 & 43,6 & 0 & 0 \\
\hline$>$ 6 tháng & 0 & 0 & 39 & 35,5 & 3 & 2,7 \\
\hline Tống & 4 & 3,6 & 103 & 93,6 & 3 & 2,7 \\
\hline
\end{tabular}

Nhận xét: Viêm lợi mức độ 1 chỉ có ở phụ nữ mang thai dưới 3 tháng, mức độ 2 tập trung ở cả 3 nhóm tuổi thai, nhưng cao nhất ở 3 tháng giữa thai kì (43,6\%), mức độ 3 chỉ có ở nhóm tuổi thai 3 tháng cuối. Sự khác biệt giữa các nhóm tuổi thai có ý nghĩa thống kê với $p<0,05$.

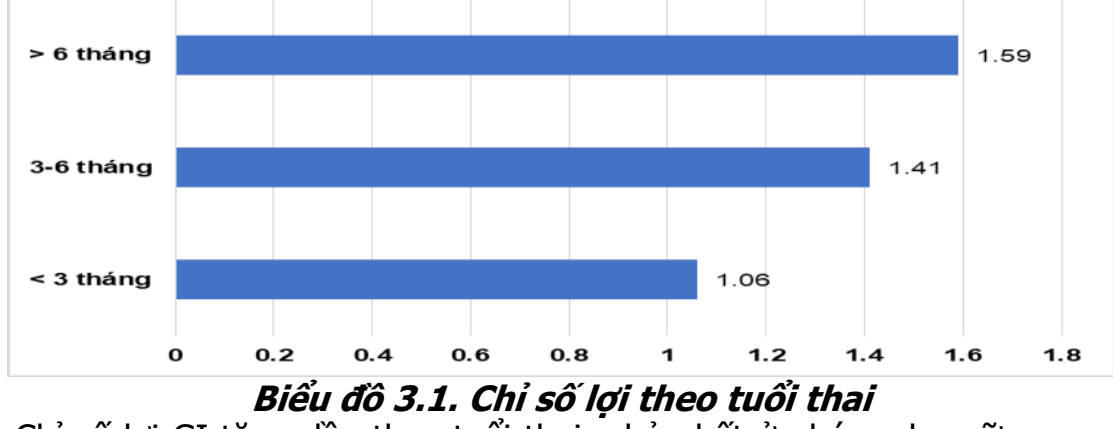

Nhận xét: Chỉ số lợi GI tăng dần theo tuổi thai, nhỏ nhất ở nhóm phụ nữ mang thai < 3 tháng $(0,88)$ và cao nhất ở nhóm phụ nữ mang thai > 6 tháng $(1,59)$. Sự khác biệt có ý nghĩa thống kê với $\mathrm{p}<0,001$.

Bảng 3.3. Phân bố mức độ mảng bám theo tuổi của phụ nữ mang thai

\begin{tabular}{|c|c|c|c|c|c|c|c|c|}
\hline \multirow[b]{2}{*}{ Tuổi } & \multicolumn{2}{|c|}{ PI đô 0} & \multicolumn{2}{|c|}{ PI độ 1} & \multicolumn{2}{|c|}{ PI độ 2} & \multicolumn{2}{|c|}{ PI độ 3} \\
\hline & $\begin{array}{c}\text { Số } \\
\text { lượng }\end{array}$ & Tỷ lệ & $\begin{array}{c}\text { Số } \\
\text { lượng }\end{array}$ & Tỷ lệ & $\begin{array}{c}\text { Số } \\
\text { lươong }\end{array}$ & Tỷ lệ & $\begin{array}{c}\text { Số } \\
\text { Iượng }\end{array}$ & Tỷ lệ \\
\hline $20-29$ tuối & 0 & 0 & 7 & 6,4 & 47 & 42,7 & 4 & 3,6 \\
\hline $30-39$ tuối & 0 & 0 & 3 & 2,7 & 26 & 23,6 & 7 & 6,4 \\
\hline >40 tuối & 0 & 0 & 1 & 0,9 & 14 & 12,8 & 1 & 0,9 \\
\hline Tống & $\mathbf{0}$ & $\mathbf{0}$ & 11 & 10,0 & 87 & 79,1 & 12 & 10,9 \\
\hline
\end{tabular}

Nhận xét: Tất cả phụ nữ mang thai đều có mảng bám răng và chủ yếu ở mức độ 2 (79,1\%). Phụ nữ mang thai có mảng bám ở mức độ 1 và 3 có tỷ lệ tương đương nhau $(10,0 \%$ và 10,9\%). Ở mức độ 2, nhóm phụ nữ mang thai có độ tuổi 20-29 chiếm tỷ lệ cao nhất (42,7\%), tiếp theo là nhóm 30 39 tuổi $(23,6 \%)$, thấp nhất là nhóm >40 tuổi (12,8\%). Tuy nhiêm sự khác biệt không có ý nghĩa thống kê với $p>0,05$.

Bảng 3.4. Phân bố mức độ mảng bám theo tuổi thai

\begin{tabular}{|c|c|c|c|c|c|c|c|c|}
\hline \multirow{2}{*}{ Tuối thaíc độ } & \multicolumn{2}{|c|}{ PI đô 0} & \multicolumn{2}{|c|}{ PI độ 1} & \multicolumn{2}{|c|}{ PI độ 2} & \multicolumn{2}{|c|}{ PI độ 3} \\
\hline & $\begin{array}{c}\text { Số } \\
\text { lượng }\end{array}$ & Tỷ lệ & $\begin{array}{c}\text { Số } \\
\text { lượng }\end{array}$ & Tỷ lệ & $\begin{array}{c}\text { Số } \\
\text { lượng }\end{array}$ & Tỷ lệ & $\begin{array}{c}\text { Số } \\
\text { lượng }\end{array}$ & Tỷ lệ \\
\hline <3 tháng & 0 & 0,0 & 5 & 4,5 & 1 & 0,9 & 0 & 0,0 \\
\hline 3-6 tháng & 0 & 0,0 & 6 & 5,5 & 53 & 48,2 & 3 & 2,7 \\
\hline$>6$ tháng & 0 & 0,0 & 0 & 0,0 & 33 & 30,0 & 9 & 8,2 \\
\hline Tống & 0 & 0,0 & 11 & 10,0 & 87 & 79,1 & 12 & 10,9 \\
\hline
\end{tabular}

Nhận xét: Nhóm phụ nữ mang thai < 3 tháng không có mảng bám mức độ 0 và độ 3. Nhóm phụ nữ mang thai 3-6 tháng không có mảng bám mức độ 0 . Nhóm phụ nữ mang thai > 6 tháng chỉ có mảng bám mức độ 2 và độ 3 . Sự khác biệt mức độ mảng bám giữa các nhóm tuổi thai có ý nghĩa 
thống kê với $p<0,05$.

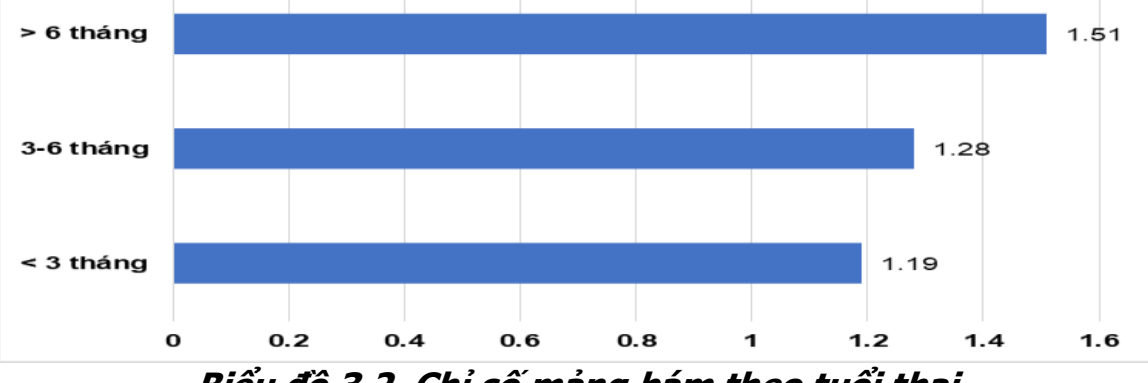

Biểu đồ 3.2. Chỉ số mảng bám theo tuổi thai

Nhận xét: Chỉ số mảng bám tăng dần theo tuổi thai, nhóm phụ nữ mang thai <3 tháng có chỉ số PI là 1,19; nhóm phụ nữ mang thai 3-6 tháng có chỉ số PI là 1,28 và nhóm phụ nữ mang thai $>6$ tháng có chỉ số PI là 1,51 . Sự khác biệt chỉ số mảng bám giữa các nhóm có ý nghĩa thống kê với $p$ $<0,001$

Bảng 3.5. Phân bố chỉ số GI và PI theo nhóm răng

\begin{tabular}{|c|c|c|c|}
\hline Chỉ số $\quad$ Nhóm răng & Nhóm răng cửa & Nhóm răng hàm & p \\
\hline Chỉ số GI & $1,52 \pm 0,25$ & $1,25 \pm 0,27$ & $p<0,001$ \\
\hline Chỉ số PI & $1,39 \pm 0,27$ & $1,41 \pm 0,26$ & $p<0,001$ \\
\hline
\end{tabular}

Nhận xét: Chỉ số lợi GI vùng răng cửa lớn hơn so với vùng răng hàm và ngược lại, chỉ số mảng bám PI vùng răng hàm lớn hơn so với vùng răng cửa. Sự khác biệt giữa 2 nhóm có ý nghĩa thống kê với $p<0,001$.

\section{BÀN LUÂ̂N}

Trong nghiên cứu của chúng tôi, viêm lợi mức độ 2 chiếm tỷ lệ cao nhất $(93,6 \%)$, tiếp theo là viêm lợi độ 1 chiếm 3,6\% và độ 3 chiếm $2,7 \%$ (bảng 3.1). Kết quả này phù hợp với kết quả của Nguyễn Đức Thiền và Trần Tấn Tài (2018) với tỷ lệ viêm lợi mức độ trung bình là $95,7 \%$ và viêm lợi nhẹ là $4,3 \%$, ở nghiên cứu này không có trường hợp viêm lợi mức độ nặng [5]. Nghiên cứu của Diawara $O$ và cộng sự tại Mali năm 2018, tỷ lệ viêm lợi trên phụ nữ mang thai là $90,9 \%$ và viêm lợi mức độ 2 cũng chiếm tỷ lệ cao nhất $(76,1 \%)[6]$.

Phân bố mức độ viêm lợi theo tuổi của phụ nữ mang thai, kết quả tại bảng 3.1 cho thây ở độ tuổi 20-29 không có phụ nữ mang thai mắc viêm lợi độ 3; độ tuổi 30 - 39, tỷ lệ mắc viêm lợi độ 2 là cao nhất $(91,6 \%)$ và không có ai viêm lợi ở mức độ 1 . Ở độ tuổi trên 40 tuổi, $100 \%$ phụ nữ mang thai mắc viêm lợi mức độ 2 . Theo nghiên cứu của Burt, tuổi tác con người tăng lên làm tăng khả năng tích tụ mảng bám và cao răng, qua đó những người lớn tuổi hơn có hiện tượng tiêu xương và mất bám dính nhiều hơn so với người trẻ tuổi. Tuy nhiên chỉ riêng yếu tố tuổi tác ở mô nha chu khoẻ mạnh không thể gây tiêu xương và mất bám dính trầm trọng.

Theo tuổi thai, kết quả tại bảng 3.2 cho thây viêm lợi mức độ 2 là chủ yếu và tập trung ở cả 3 nhóm tuổi thai, nhưng cao nhất ở 3 tháng giữa thai kì (43,6\%). Ở PNMT khi bắt đầu bước vào 3 tháng giữa và 3 tháng cuối thai kì, nồng độ hormone progesterone và estrogen bắt đâu tăng cao hơn so với 3 tháng đầu. Ở phụ nữ mang thai nồng độ hormone estrogen và progesterone dần dần tăng cao do hoàng thể tiết ra từ lúc bắt đầu có thai và sau đó là do nhau thai tiết ra. Tới 3 tháng cuối thai kỳ, progesterone và estrogen đạt đỉnh với nồng độ 100 và $6 \mathrm{ng} / \mathrm{ml}$, tăng gấp 10-30 lần so với thời kỳ kinh nguyệt. 2 hormone này là yếu tố tăng trưởng, tạo thuận lợi cho sự phát triển vi khuẩn Prevotella Intermedia gây viểm lợi. Kết quả nghiên cứu của chúng tôi cũng tương tự như nghiên cứu của Diawara O tại Mali [6]. Trong nghiên cứu này, nhóm phụ nữ mang thai 3 tháng giữa và 3 tháng cuối thai kỳ có tỉ lệ viêm lợi mức độ 2 cao nhất $(73,2 \%$ và $77,3 \%)$, các mức độ viểm lợi còn lại chiếm tỷ lệ thấp.

Về chỉ số lợi, trong nghiên cứu của chúng tôi chỉ số GI tăng dần theo tuổi thai, sự khác biệt giữa các nhóm có ý nghĩa thống kê với $p<0,01$ (biểu đồ 3.1). Điều đó cho thấy thây sự tăng nồng độ hormone progesterone và estrogen làm tăng nặng mức độ viêm lợi ở phụ nữ mang thai. Trong nghiên cứu của Trần Tấn Tài và Nguyễn Đức Thiền (2018), chỉ số GI theo 3 giai đoạn của thai kì lần lượt là 1,$44 ; 1,6$ và 1,55 [5]. Nghiên cứu của Gonzalez - Jaranay M (2017) cho thấy 
chỉ số GI ở giai đoạn thai 21-23 tuần (3 tháng giữa) tăng $66,3 \pm 0,17 \%$, giai đoạn thai 34-36 tuần (3 tháng cuối) tăng $74,5 \pm 0,18 \%$ so với mốc ban đầu [7].

Đối với chỉ số mảng bám, trong nghiên cứu của chúng tôi chỉ số mảng bám tăng dần theo tuổi thai, sự khác biệt giữa các nhóm có ý nghĩa thống kê khi $p<0,01$ (biểu đồ 3.2). Mặc dù không có sự khác biệt về mức độ mảng bám theo tuổi của phụ nữ mang thai (bảng 3.3), nhưng theo tuổi thai mức độ mảng bám ở giai đoạn 3 tháng cuối thai kì cao hơn so với 3 tháng đầu (bảng 3.4). Vì vậy chỉ số mảng bám sẽ tăng dần theo tuối thai. Kết quả này cũng phù hợp với kết quả nghiên cứu của Gonzalez - Jaranay $\mathrm{M}$ tiến hành nghiên cứu trên 96 phụ nữ mang thai [7]. Tác giả nhận thấy có sự gia tăng chỉ số mảng bám trong quá trình mang thai: tỷ lệ mảng bám tăng $42,6 \pm$ $0,14 \%$ ở 3 tháng giữa và $45,6 \pm 0,13 \%$ ở 3 tháng cuối thai kỳ so với mốc ban đâu.

Khi so sánh chỉ số GI và PI giữa các nhóm răng ta có thể thấy nhóm răng phía trước có chỉ số GI cao hơn so với nhóm răng phía sau $(1,52$ so với 1,39$)$, tuy nhiên chỉ số PI lại thấp hơn $(1,25$ với nhóm răng trước và 1,41 với nhóm răng sau). Điều này phù hợp với kết quả của Löe, H., \& Silness (1963) cho rằng nhóm răng phía trước có sự gia tăng chỉ số GI lớn nhất so với nhóm răng sau và vùng kẽ răng có chỉ số GI cao nhất so với các vùng còn lại.

\section{KẾT LUẬN}

Trong nghiên cứu này, phụ nữ mang thai chủ yếu mắc viêm lợi mức độ 2 . Mức độ viêm lợi với chỉ số GI và mức độ mảng bám với chỉ số PI tăng dần theo tuổi thai. Mức độ viêm lợi cũng tăng theo tuổi phụ nữ mang thai. Mức độ viêm lợi ở nhóm răng phía trước nặng hơn so với nhóm răng phía sau.

\section{TÀI LIÊU THAM KHẢO}

1. Lunardelli A.N., Peres M.A (2005). Is there an association between periodontal disease, premature and low birth weight? A populationbased studv. J.Clin.Periodontal, 32(9):938-946.

2. Ide M, Papapanou PN. (2013). Epidemioloav of association between maternal periodontal disease and adverse preqnancy outcomes-systematic review. J Periodontol, 84(4 Suppl):Ș181-S194.

3. Trần Văn Trường, Lâm Ngọc Ẩn, Trịnh Đình Hải và cộng sự (2001). Điêuu tra sức khỏe răng miệng toàn quốc, Nhà xuất bản Y học - Hà Nội.

4. Marta Silveira da Mota Krüger, Renata Picanço Casarin, et al (2017). Periodontal Health Status and Associated Factors: Findings of a Prenatal Oral Health Program in South Brazil. International Journal of Dentistry. 2017:3534048.

5. Nguyển Đức Thiên, Trân Tấn Tài (2018). Thực trạng bệnh nha chu, kiến thức, thái độ, thực hành và nhu câu điều trị ở phụ nữ mang thai. Tạp chí Y Dược học - Trường Đại học Y Dược Huế Tập 8, số 6.

6. Diawara 0 , Kane et al (2018). Periodontal Health in Pregnant Women Study of 208 Pregnancies at Chu Gabriel Touré. Bamako. Mali. Dentistry and Pratices, 1(1): 001-004.

7. Maximino Gonzalez-Jaranay, Luis Tellez, Antonio Roa-Lopez, et al (2017). Periodontal Status during pregnancy and postpartum. Plos One. 12(5): e0178234.

\title{
PHÁT TRIỂN VÀ ÁP DỤNG XÉT NGHIỆM DI TRUYỀN TRƯớC CHUYỂN PHÔI (PGT-M) CHO BÊ̂NH THALASSEMIA Ở VIẸT NAM
}

\author{
Đào Mai Anh ${ }^{1}$, Gary L Harton ${ }^{2}$, Nguyễn Quang Vinh', \\ Nguyễn Văn Huynh ${ }^{1}$, Hoàng Thị Nhung ${ }^{1}$, Phạm Thúy Nga ${ }^{3}$, \\ Lê Thị Thu Hiền ${ }^{4}$, Nguyễn Minh Đức ${ }^{4}$, Trẩn Quốc Quân ${ }^{1}$
}

\section{TÓM TẮT}

Mục tiêu: Thiết kế, tối ưu và xây dựng quy trình cho thực hiện đồng thời xét nghiệm PGT-A và PGT-M cho bệnh thalassemia, sử dụng hệ thống giải trình tự

${ }^{1}$ Công ty Cổ phần Dịch vụ Phân tích Di truyền GENTIS 2PerkinElmer Health Sciences Australia ${ }^{3}$ Bênh viện Phụ Sản Hà Nối

${ }^{4}$ Bệnh viện Nam học \& Hiếm muộn Hà Nội

Chịu trách nhiệm chính: Nguyễn Quang Vinh

Email: vinhnq@gentis.com.vn

Ngày nhâan bài: 4.01 .2021

Ngày phản biện khoa học: 1.3.2021

Ngày duyệt bài: 12.3.2021 thế hệ mới cho phép kiểm tra đồng thời các đột biến trong gen $\mathrm{HBB}$ và các dấu chuẩn đa hình đơn nucleotide (SNP). Phương pháp: Thiết kế và tối ưu quy xét nghiệm kết hợp PGT-A và PGT-M cho bệnh nhân IVF tại Việt Nam, trong đó xét nghiệm thực hiện sử dụng hể thống giải trình tự thế hể mới cho phẻp kiểm tra các đột biến gây bệnh beta-thalassemia đông thời cùng lương lớn các đa đình SNP sử dung cho phân tích di truyền liên kết và kiểm soát nhiếm chéo. Kết quả: Đến nay, 2 trường hợp đã hoàn thành toàn bộ quy trình bao gồm cả chuyển phôi trong khi 9 trường hợp khác đã hoàn thành phân tích IVF và PGTM/A nhưng vẫn chưa hoàn thành chuyển phôi. Trong 2 trường hợp được chuyển phôi, cả 2 bệnh nhân đều có thai với phôi thai không mang bất thường dị bội và 